\section{When things go wrong}

\section{Aboard the Polar Duke}

To be a biologist studying the ocean food web in Antarctica, it helps to know how to weld. Underwater monitoring stations must be attached to all the scrap iron in sight to keep them from being dragged away by icebergs. Some experience in sonar electronics is also handy, as is a familiarity with satellite navigation, especially when trying to find a station that has spent a year under water. And when the devices will not respond to acoustic release commands, a thorough knowledge of salvage techniques is essential, including a working familiarity with a grappling hook.

Those are the lessons from one ill-fated recovery exercise, an all-too-typical example of how things can go wrong in Antarctica.

David Karl is studying the carbon cycle in the Antarctic, from the algae and krill down to the sediment. Just how much of the carbon-based life near the surface of the Southern Oceans actually reaches the sediment is one of the great unknowns of the climate change equation. To explore the particular question, the University of Hawaii molecular biologist placed several sediment traps - essentially upside-down funnels with collection jars at the bottom - at various sites near the Antarctic Peninsula to record the amount of living matter that falls through the water column in a year.

Dropping the sediment traps was easy Karl and his colleagues wrapped an old boiler with 15 metres of iron-link chain, tied it to cable on which two traps and some floats were attached, and threw it overboard.

That was last year. This February it was time to recover the traps and see what they had caught. The National Science Foundation icebreaker Polar Duke scheduled a brief detour to pick up the traps on its way from King George Island down the peninsula to Palmer Station.

Modern traps - indeed, most modern underwater recoverable objects - are designed to be released remotely, by sending a special acoustic signal. The traps (actually electronics in the mooring to which the traps are attached) put out a weak locator signal so that one can place an acoustic transducer essentially an underwater loudspeaker near enough to be heard, but not so near that the whole thing pops up under the boat.

But when the Polar Dukereached the area where the traps were supposed to be, Karl could not pick up the locator signal. He sent the release signal anyway, in the hope that it was just the transmission portion of the trap's electronics that had failed, but the icy waters remained unbroken.

At this point, one might have been tempted to give up. The only way to recover a trap that will not come up on its own is to drag for it with a grappling hook, a centuryold technique that basically means putting a lethal-looking iron hook overboard and cruising back and forth until it snags something. (Things go wrong so routinely in the Antarctic that there has even emerged a term - 'plan Z' - to describe the necessary use of methods so far-fetched that they would be ridiculed elsewhere.)

Normally, the odds of the hook working are astronomical. It is, after all, a big ocean.

But Karl still had some technology up his sleeve. When he had dropped the traps a year earlier, he had recorded their position with the use of the Global Positioning System (GPS), the worldwide satellite network that the US Department of Defense has set up to (among other things) guide cruise missiles.

Without a special military decoder, GPS coordinates are accurate only to several tens of metres. But even that is a great leap up from map readings or celestial bearings. With GPS as his guide, Karl decided he could get close enough to the traps (assuming they had not moved) to raise the odds of snagging them to an acceptable risk.
That, however, would have to wait until the Polar Dukereturned, nearly a week later. Early one morning on the return voyage, the Polar Duke arrived again at the site, with a grappling apparatus ready to be deployed. The hook (a home-made three-metre bar with four three-prong barbs on chains, adorned with the stencilled words 'Claws-oDeath') was lowered into the water shortly before noon.

After less than an hour's searching, the Polar Duke's sonar recorded a series of objects vertically separated by some 30 metres - the acoustic profile of the sediment traps. Within seconds the winch operator also reported tension on the grappling line and the icebreaker slowed to a stop.

The winch slowly pulled up the hooks as Karl and the crew of the Polar Duke leaned over the rail searching for a glimpse of the yellow floats of the traps. Several long minutes later, the floats surface was 100 metres behind the ship, to cheers.

After another 30 metres of cable was winched in, the upper trap surfaces and has hoisted above the stern deck of the icebreaker. The researchers surrounded it, examining the 13 collection jars on its rotating carousel. All but one of the jars were virtually empty - more proof that this part of the Antarctic Ocean has experienced no algae bloom this year, something researchers elsewhere had already observed.

The crew turns back to the cable still stretched over the edge. One hundred metres below hung the second trap, and 100 metres below that, damaged the boiler and chains, encrusted with over a ton of silt from a year under water. Observers on the upper deck, watching the tension in the stressed wire, moved back, lest it break and whip towards them.

The winch was started again, slowly, and the cable again began to reel in. But by now the stress dynamics of the cable had changed. As the cable shortened, it also became less elastic, and with every pitch of the ship, the weight below pulled it to its breaking point. Finally, with a groan, the wire parted, and the weights, the second trap, and 200 metres of cable plummeted to the ocean bottom.

An effort was made to drag again, this time on the ocean floor, but after a frustrating hour, the Claws-o-Death was reeled back in, beaten by underwater rocks into twisted junk. Karl gave up.

"The important thing is the data", he says. The traps cost $\$ 16,000$ each, but the sediment record they hold is worth far more. Data from the upper trap will answer the most pressing questions about sediment in the region, but the loss of the lower trap is a disappointment. Frustrating, too, is the loss of the mooring, which was the cause of all the trouble. Karl will be back again to drop other sediment traps, but without knowing what caused this one to fail, he has to eventually expect another afternoon with the grappling hook.

C.A. 